\title{
A case report of a congenital immune deficiency disease - WHIM syndrome
}

\author{
Sohrab Aghabeigi ${ }^{1 *}$, Mitra Ranjbar ${ }^{2}$, Fatemah Tahanian ${ }^{1}$ and Ahmad Hezarjaribi ${ }^{1}$ \\ ${ }^{1}$ Department of Internal Medicine, Iran University of Medical Sciences, Tehran, Iran \\ ${ }^{2}$ Department of Infectious Diseases, Iran University of Medical Sciences, Tehran, Iran
}

\begin{abstract}
Background: WHIM syndrome is a rare primary immunodeficiency disorder. WHIM is an acronym for some of the characteristic symptoms of the disorder; warts, hypogammaglobulinemia, infections, and myelokathexis.

Case-report: A 23-year-old male with a history of recurrent cutaneous and respiratory tract infections -since early childhood- was presented with chronic productive cough, fever, pleuritic chest pain, chills and sweating. Preclinical investigation showed leukopenia, neutropenia, myelokathexis and hypogammaglobulinemia. Patient was diagnosed for WHIM syndrome he also had a positive HBs Ag with normal LFT tests. He was treated with Ciprofloxacin, Vancomycin and IVIG but due to withdrawing the next sessions of IVIG; he was admitted 2 more times with respiratory tract infection and pneumonia that was treated with antibiotics and IVIG again and was discharged with good condition. He is on monthly IVIG and tenofovir because of being HBs Ag positive.
\end{abstract}

Conclusion: This case report provides data of a patient with recurrent respiratory and cutaneous infection who was diagnosed with WHIM syndrome and had a positive $\mathrm{Hbs} \mathrm{Ag}$ However, his liver function test was normal.

Abbreviations: WHIM: Warts, hypogammaglobulinemia, infections and myelokathexis; HPV: Human papilloma virus; HBV: Hepatitis B virus.

\section{Background}

WHIM syndrome is a rare primary immunodeficiency disorder characterized by irregularities in the cell development and/or cell maturation process of the immune system specially neutrophils and WHIM is an acronym for some of the characteristic symptoms of the disorder (w)arts, (h)ypogammaglobulinemia, (i)nfections, and (m) yelokathexis [1].

Approximately 40 cases of this syndrome have been reported until now. WHIM syndrome is an autosomal dominant trait resulting from mutations in the CXC chemokine receptor 4 (CXCR4, MIM \#162643) gene [1-3]. CXCR4 is involved in organogenesis, hematopoiesis, and immune responses but these Mutations in the CXCR4 gene are not present in all patients with WHIM syndrome. In such patients, the syndrome may be due to defects in components involved in CXCR4 internalization and desensitization, such as the $G$ protein-coupled receptor kinase 3 (GRK3) and arrestin-beta-2 (ARRB2) that leads to enhanced leukocyte responsiveness to CXCL12 [4-7].

Individuals with WHIM syndrome are more susceptible to potentially life-threatening bacterial infections. they are also predisposed to viral infections. Affected individuals are particularly susceptible to human papilloma virus (HPV), which can cause skin and genital warts and potentially lead to cancer and also hepatitis $B$ virus (HBV) that may cause hepatitis and liver disorders presenting with rising liver enzymes [6-8]. Affected individuals have extremely low levels of neutrophils $[7,8]$. The symptoms of WHIM syndrome can vary greatly from one individual to another. Some patients may have mild expression of the disorder; others may develop potentially lifethreatening complications [8]. Generally, symptoms first appear in early childhood when most children with WHIM syndrome experience repeated bacterial infections that can be mild or severe, but usually respond promptly to antibiotic therapy. Hepatitis B virus (HBV) infection is more frequent in immune deficient populations than general population. they also have lower rates of spontaneous recovery in acute cases; thus explaining the high rate of chronic infection and the increased risk of cirrhosis and hepatocellular carcinoma, resulting in increased morbidity-mortality in these patients. The negative impact of immune deficiency on chronic HBV infection is related to high viral load that enhances the progression of fibrosis and may result in a rare severe liver disease called fibrosing cholestatic hepatitis, which reflects the direct toxicity of high levels of HBV proteins Thus, immune deficiency enhances the hepatitis B viral load, which results in the progression of fibrosis and/or acute exacerbation of underlying liver disease (HBV reactivation) on one hand, whereas reduction in immune deficiency may also be harmful because of immune restoration on the other hand.

${ }^{*}$ Correspondence to: Sohrab Aghabeigi, MD, Department of Internal Medicine, Iran University of Medical Sciences, Tehran, Iran. E-mail: doctorsohrabaghabeigi@gmail.com

Key words: WHIM syndrome, CXCR4, myelokathexis, neutropenia, hypogammaglobulinemia, human papilloma virus, warts

Received: November 27, 2019; Accepted: December 09, 2019; Published: December 11, 2019 


\section{Objective}

The purpose of this paper is to represent a patient with WHIM syndrome who is $\mathrm{Hbs} \mathrm{Ag}$ positive. However, his liver function test is normal.

\section{Case presentation}

A 23-year-old man was admitted in FIROOZGAR HOSPITAL. At the time of admission his problems were chronic productive cough, fever, pleuritic chest pain, chills and sweating. Cefixime was prescribed for him in an outpatient clinic. However his condition has not improved and from a week before his admission; coughing and fever were increased and a $2+$ lower extremity pitting edema has emerged. He had a history of recurrent cutaneous and respiratory tract infections since his childhood and a previous thorax surgery in order to drainage an abscess.

In physical examination multiple warts were detected on phalanges of both hands and A 3/6 systolic heart murmur and rhonchi in base of left lung were auscultated.

Laboratory tests revealed leukopenia (WBC count 2000 per $\mathrm{mm}^{3)}$ and neutropenia (absolute neutrophil count 1400 per $\mathrm{mm}^{3}$ ) compatible with myelokathexis. IgG and IgA levels were substantially low as they were 200 and $400 \mathrm{mg} / \mathrm{dl}$, respectively. meaning that he was hypogammaglobulinemic (Tables 1 and 2).

He has been examined for viral markers e.g. HBs Ag, HCV Ab, HIV $\mathrm{AB}$ and blood and sputum culture for $\mathrm{TB}$ that were all negative except HBs Ag. His LFT results unexpectedly showed SGPT and SGOT of 16 (IU/L) and 17 (IU/L), respectively as shown in (Table 3).

In pathologic assessment of gastrointestinal tract active duodenitis was diagnosed. Bone marrow aspiration and biopsy showed no abnormality except myeloid hyper cellularity changes.

He was treated with Ciprofloxacin, Vancomycin, IVIG and discharged in good condition. 40 days later he came to daycare unit to receive second session of IVIG.

He did not come back for receiving the third session of IVIG resulting hospital admission due to fever and productive cough 4 months later. once again various antibiotics were prescribed for him and he was discharged in good general condition with no especial problem (LAB data at the time of discharge is showed in Table 4).

After that he received IVIG regularly with interval of a month for 6 times but once again he didn't come back to receive IVIG for 8 months and as a result he was admitted with myalgia, productive cough, coryza, wheeze and dyspnea. Work up was done in order to rule out pneumonia and sinusitis; sinus CT scan showed opacity and bilateral paranasal sinus mucosal thickening that leaded to OMS obstruction (Figure 1, sinus CT-scan). Lung CT illustrated a $6 \mathrm{~mm}$ nodule in lateral segment of right middle lobe, multiple sub pleural nodules and a $5.5 \mathrm{~mm}$ nodule in laterobasal segment of left lower lobe. The right $8^{\text {th }}$ rib had been resected posteriorly and laterally suggesting previous surgery. Vascular and bronchial diameter was normal. There was no evidence of pleural effusion, lymphadenopathy in lung hilum and mediastinum (Figure 2, chest CAT-scan). He received IVIG, meropenem and was discharged with fluticasone inhaler, pseudoephedrine syrup, ketokifen tablet, Cefixime and Pantoprazole.

Once again he has been discharged with good general condition with no sepecial problem.
Now he is on regular IVIG regimen monthly. He is also on tenofovir because of being HBS ag positive.

Table 1. Serology and immunology lab data in first admission

\begin{tabular}{|c|c|c|}
\hline Test & Result & Reference value \\
\hline Anti CCP Unit/ml & 0.8 & Positive $>5$ \\
\hline $\mathrm{C} 3(\mathrm{mg} / \mathrm{l})$ & 117 & $90-180$ \\
\hline $\mathrm{C} 4(\mathrm{mg} / \mathrm{l})$ & 50 & $10-140$ \\
\hline $\mathrm{CH} 50 \%$ & 140 & $70-150$ \\
\hline $\mathrm{TTG} \mathrm{Ab}(\mathrm{Unit} / \mathrm{ml})$ & 0.5 & Negative $<10$ \\
\hline $\mathrm{IgG} 1(\mathrm{mg} / \mathrm{dl})$ & 46 & $315-855$ \\
\hline $\mathrm{IgG} 2(\mathrm{mg} / \mathrm{dl})$ & 7 & $23-196$ \\
\hline $\operatorname{IgG} 3(\mathrm{mg} / \mathrm{dl})$ & 20 & $64-495$ \\
\hline $\operatorname{IgG} 4(\mathrm{mg} / \mathrm{dl})$ & 3 & $11-157$ \\
\hline $\mathrm{CRP}(\mathrm{mg} / \mathrm{l})$ & 54 & \\
\hline & & \\
\hline
\end{tabular}

Table 2. WBC count and diff in first admission

\begin{tabular}{|c|c|c|c|}
\hline $\mathrm{WBC} / \mathrm{mm}^{3}$ & 2000 & 1800 & 1600 \\
\hline Lymphocyte \% & 20 & 23.9 & 44 \\
\hline Segment \% & 70 & 70.6 & 46.9 \\
\hline Mix \% & 1.5 & 5.5 & 9 \\
\hline $\mathrm{Hb} \mathrm{mg/dl}$ & 8.5 & 9 & 8.9 \\
\hline Platelet $/ \mathrm{mm}^{3}$ & 204000 & 108000 & 87000 \\
\hline
\end{tabular}

Table 3. Liver function test in first admission

\begin{tabular}{|c|c|}
\hline AST (IU/L) & 17 \\
\hline ALT (IU/L) & 16 \\
\hline ALK P (IU/L) & 183 \\
\hline Direct bilirubin $(\mathrm{mg} / \mathrm{dl})$ & 79 \\
\hline Total bilirubin $(\mathrm{mg} / \mathrm{dl})$ & 0.155 \\
\hline
\end{tabular}

Table 4. Lab data at time of second discharge

\begin{tabular}{|c|c|}
\hline WBC/mm3 & 4900 \\
\hline Lymphocyte \% & 19.2 \\
\hline Segment \% & 64.7 \\
\hline Mix \% & 16.1 \\
\hline Hb mg/dl & 9.5 \\
\hline Platelet $/ \mathrm{mm} 3$ & 206000 \\
\hline
\end{tabular}

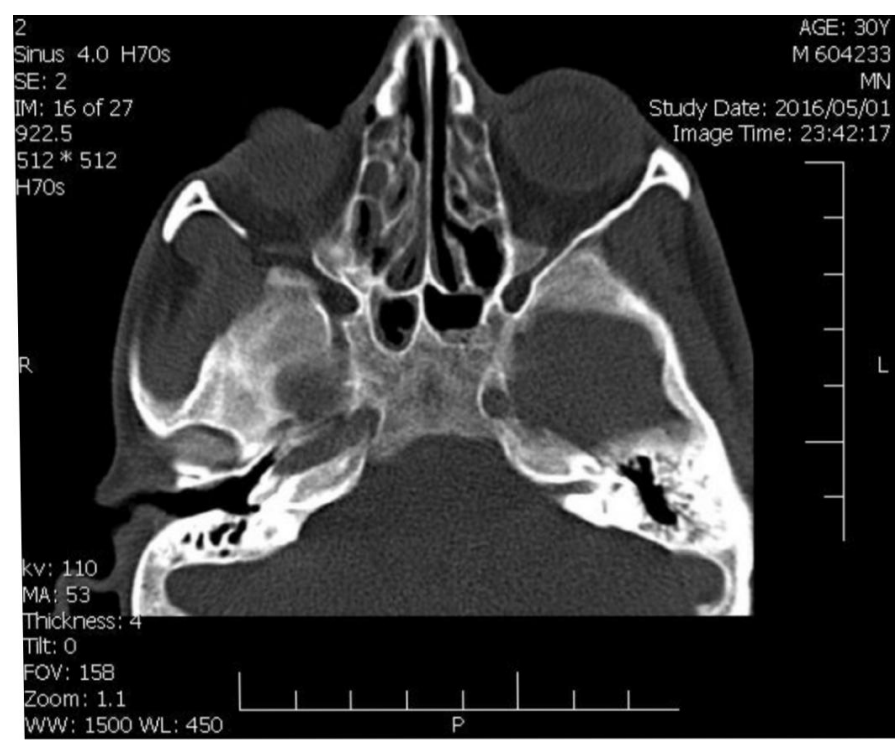

Figure 1. Sinus CT scan 


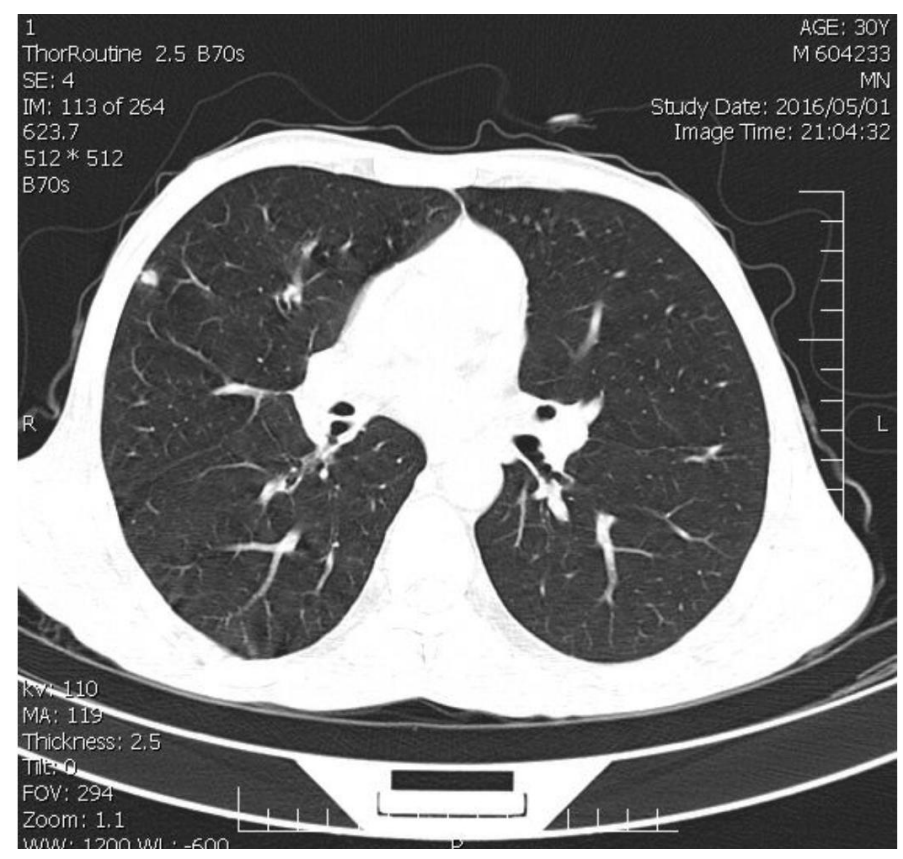

Figure 2. Chest CT scan

\section{Discussions}

WHIM syndrome is an inherited immune deficiency which is characterized by neutropenia, myelokathexis and hypogammaglobulinemia. recurrent infections, can cause considerable susceptibility to human papilloma virus infection with resultant warts.

There is emerging evidence that WHIM syndrome results from functional hyperactivity of CXCR4. Hyperactivity of CXCR4 on mature neutrophils in the bone marrow may prevent their release from the marrow, resulting in peripheral blood neutropenia. Data provided by previous case reports suggest that warts $78.6 \%$, hypogammaglobulinemia $89.6 \%$, and neutropenia $91.7 \%$ was present in the patients [9]. In this case all of these 4 symptoms was found. clinical management of WHIM includes treatment with G-CSF, IVIG, prophylactic antibiotics, and aggressive surveillance for and surgical extirpation of dysplastic skin and mucosal HPV related lesions [1]. Immunoglobulins are used in the case of hypogammaglobulinemia but its early prophylactic use seems to have a role in preventing chronic pulmonary infection [10]. In current case withdrawing of IVIG treatment caused severe respiratory tract infection and pneumonia. chronic treatment of WHIM patients with a potent inhibitor of CXCR4 function such as Plerixafor (MOBOZIL;
AMD3100) which is also a stem cell mobilizing agent is effective in increasing circulating leukocyte, decreasing infection frequency and reducing the size of warts [11-13].

This patient had HBs Ag positive result with normal ALT and other liver function tests. In databases search we didn't find any other HBs positive case reported So this is the First time that HBs Ag positive with normal liver function is reported in a WHIM syndrome patient. Although the patient had no sign of chronic hepatitis but because of his immunodeficiency condition antiviral medication was prescribed for the patients.

\section{References}

1. Gorlin RJ, Gelb B, Diaz GA, Lofsness KG, Pittelkow MR, et al. (2000) WHIM syndrome, an autosomal dominant disorder: clinical, hematological, and molecular studies. Am J Med Genet 91: 368.

2. Zuelzer WW (1964) "Myelokathexis"-a new form of chronic granulocytopenia. Report of a case. N Engl J Med 270: 699.

3. Wetzler M, Talpaz M, Kleinerman ES, King A, Huh YO, et al. (1990) A new familial immunodeficiency disorder characterized by severe neutropenia, a defective marrow release mechanism, and hypogammaglobulinemia. Am J Med 89: 663

4. Roland J, Murphy BJ, Ahr B, Robert-Hebmann V, Delauzun V, et al. (2003) Role of the intracellular domains of CXCR4 in SDF-1-mediated signaling. Blood 101: 399.

5. Wetzler M, Talpaz M, Kleinerman ES, King A, Huh YO, et al. (1990) A new familia immunodeficiency disorder characterized by severe neutropenia, a defective marrow release mechanism, and hypogammaglobulinemia. Am J Med 89: 663.

6. Hernandez PA, Gorlin RJ, Lukens JN, et al. (2003) Mutations in the chemokine receptor gene CXCR4 are associated with WHIM syndrome, a combined immunodeficiency disease. Nat Genet 34: 70. [Crossref]

7. Leiding JW, Holland SM (2012) Warts and all: human papillomavirus in primary immunodeficiencies. J Allergy Clin Immunol 130: 1030

8. Tassone L, Notarangelo LD, Bonomi V, Savoldi G, Sensi A, et al. (2009) Clinical and genetic diagnosis of warts, hypogammaglobulinemia, infections, and myelokathexis syndrome in 10 patients. J Allergy Clin Immunol 123: 1170.

9. Kawai T, Malech HL (2009) WHIM syndrome: congenital immune deficiency disease. Curr Opin Hematol 16: 20-26.

10. Beaussant Cohen S, Fenneteau O, Plouvier E, Rohrlich PS, Daltroff G, et al. (2012) Description and outcome of a cohort of 8 patients with WHIM syndrome from the French severe chronic neutropenia registry. Orphanet J Rare Dis 7: 71. [Crossref]

11. McDermott DH, Liu Q, Ulrick J, Kwatemaa N, Anaya-O'Brien S, et al. (2011) The CXCR4 antagonist plerixafor corrects panleukopenia in patients with WHIM syndrome. Blood 118: 4957. [Crossref]

12. Dale DC, Bolyard AA, Kelley ML, Westrup EC, Makaryan V, et al. (2011) The CXCR4 antagonist plerixafor is a potential therapy for myelokathexis, WHIM syndrome. Blood 118: 4963.

13. McDermott DH, Liu Q, Velez D, Lopez L, Anaya-O'Brien S, et al. (2014) A phase 1 clinical trial of long-term, low-dose treatment of WHIM syndrome with the CXCR4 antagonist plerixafor. Blood 123: 2308. [Crossref]

Copyright: (2019 Aghabeigi S. This is an open-access article distributed under the terms of the Creative Commons Attribution License, which permits unrestricted use, distribution, and reproduction in any medium, provided the original author and source are credited. 